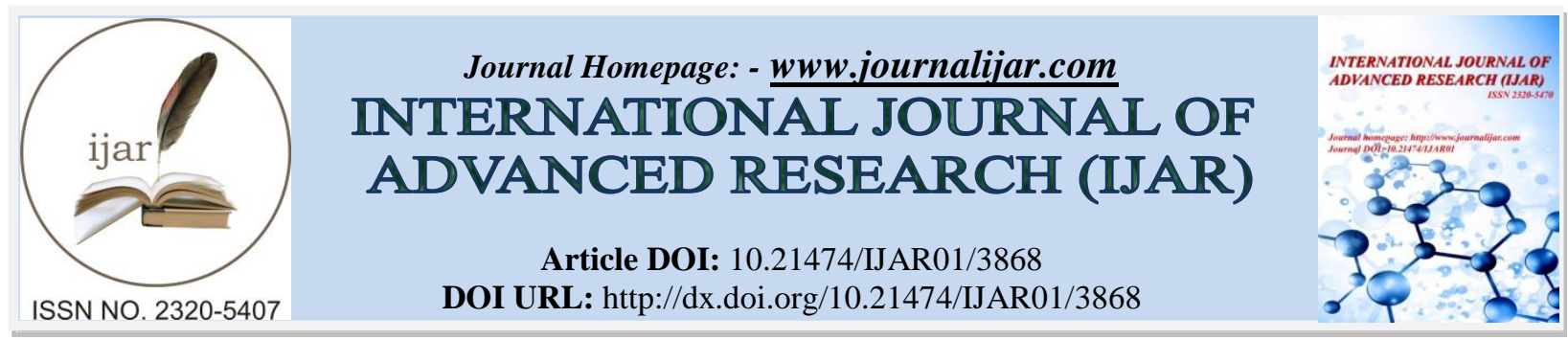

RESEARCH ARTICLE

\title{
PERFORMANCE EVALUATION OF CUSTOM POWER DEVICES TO MITIGATE VOLTAGE SAG IN POWER DISTRIBUTION NETWORK.
}

Suresh $^{1}$, Baskaran $^{2}$ and Ramya ${ }^{3}$.

1. Ph.D. Scholar, EEE Dept., Annamalai University, Chidambaram, Tamilnadu, India.

2. Professor, EEE Dept., Annamalai University, Chidambaram, Tamilnadu, India.

3. Ph.D. Scholar, EEE Dept., SRM University, Chennai, Tamilnadu, India.

\section{Manuscript Info}

\section{Manuscript History}

Received: 05 February 2017

Final Accepted: 08 March 2017

Published: April 2017

\section{Key words:-}

Dynamic Voltage Restorer (DVR),

Distributed Static Compensator

(DSTATCOM),

Distributed Power Flow Controller

(DPFC),

Interline Dynamic Voltage Restorer (IDVR),

Unified Power Flow Controller (UPFC).

\begin{abstract}
The power quality improvement has become a major concern in electrical power system. The power quality issues is very sensitive for the industrial customers. This paper describes voltage sag compensation in distributed power network by using custom power devices. Major power quality problems are created due to additional load is connected with existing load. This paper presents the modeling and simulation of DVR, DSTATCOM, UPFC, DPFC and IDVR in matlab/simulink. Switching and triggering signals for the switching devices are provided by PWM generators which are used to control the output of compensating devices. The simulation results are presented to assess the performance of each device to mitigate the voltage sag and economic device are proposed.
\end{abstract}

Copy Right, IJAR, 2017,. All rights reserved.

\section{Introduction:-}

In these days power electronics equipment's plays a vitol role in the transmission side and the homely used equipments. Thus in these power electronics equipment's power quality problems arises, due to power quality problems the life time of equipment reduces. To provide an active \& flexible solution for power quality problems, various efforts have done from time to time. Among these power quality solution lossless passive filters consists of L-C tuned component have been widely used to suppress harmonic. Passive filters are advantageous as its initial cost is low and high efficiency. On the other hand it has various drawbacks of instability, fixed compensation, resonance with supply as well as loads and utility impedance. To overcome these limitations active power filters have been used. Active power filter has various configurations: shunt, series and hybrid. Hybrid is the combination of series and shunt types. Shunt APF is used for compensating current based distortions series APF compensates voltage based distortions. Hybrid APF is applied for filtering high order harmonics. However, they have a problem that their rating is sometimes very close to load (up to load $80 \%$ ) in typical applications. Due to this reason, power quality level is not obtained. This causes power disturbances and customer dissatisfaction. To increase the reliability of the distribution system and face the power disturbance problems, an advanced power electronics controller devices have launched over last decades. The evolution of power electronics controller devices has given to the birth of custom power 


\section{Custom Power Devices:-}

Just like facts for transmission systems, the custom power device pertains to the use of power electronic controller for distributed system. The custom power devices are mainly divided into two groups: network reconfiguring type and compensating type. The complete classification of custom power devices is shown in the Fig 1.

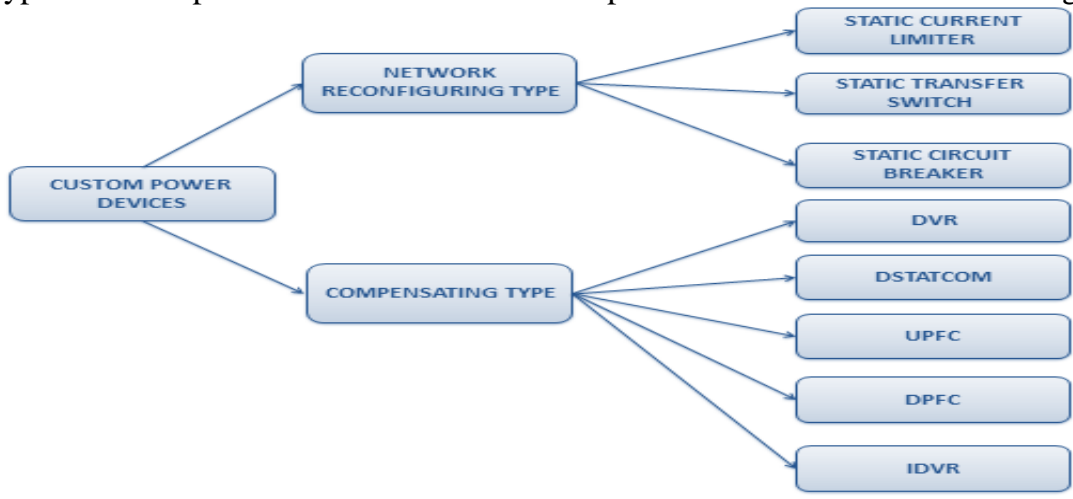

Fig 1.Classification of Custom Power Devices

Static current limiter:-

Static current limiter is a series connecting devices that reduces fault current by inserting series inductance in faulty path. It consist of a pair of GTO with snubber circuit and inductor

\section{Static transfer switch:-}

A static transfer switch uses power semiconductor such as silicon controlled rectifiers to transfer a load between two sources. It is used to protect sensitive load voltage sag or swell

\section{Static circuit breaker:-}

It includes three phase switches, each switch including a pair of power thyristor connected in inverse parallel relationship with one another and a common commutation circuit. A common surge suppressing circuit for all the switch is also provided in the static circuit breaker

\section{Simulation Of Compensating Type Custom Power Devices:- \\ Transmission Line Model at Normal Condition:-}

The Simulink model of transmission line systems with normal condition is shown in Fig 2. A power measurement block is connected in line 1 to measure real power and reactive power. The simulation output of current and voltage waveform of transmission model with normal condition is shown in Fig 3. The Simulation output of real and reactive power with normal condition is shown in Fig 4.

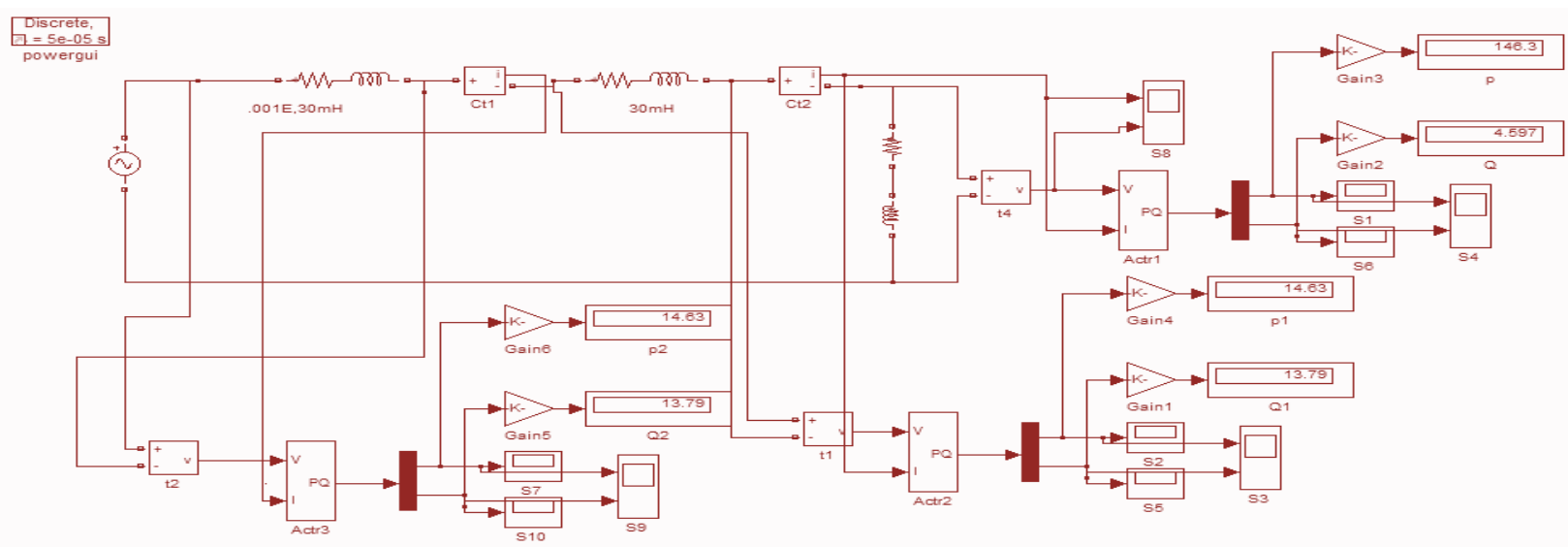

Fig 2:- Simulink model of transmission line with normal condition 


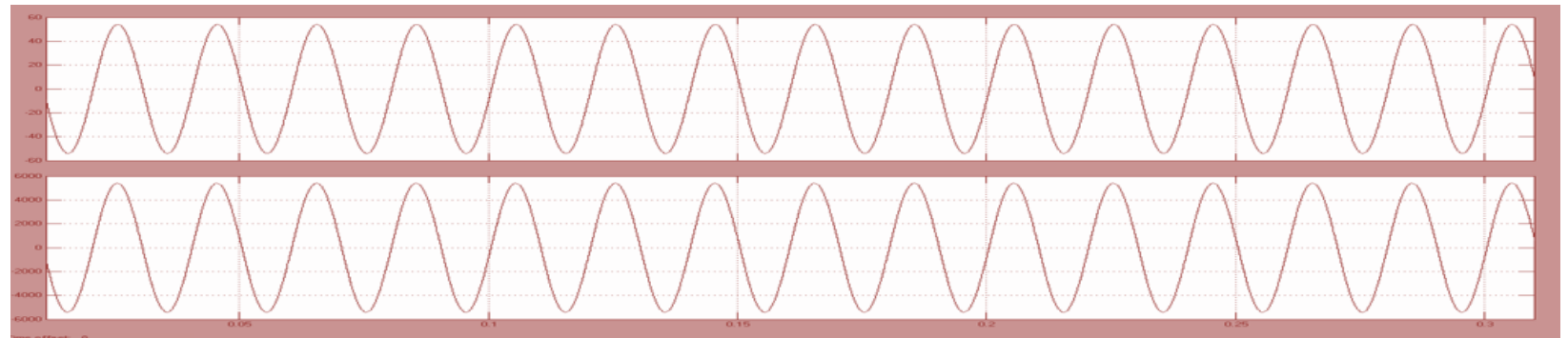

Fig 3:- Simulation output of current and voltage waveform of transmission model with normal condition

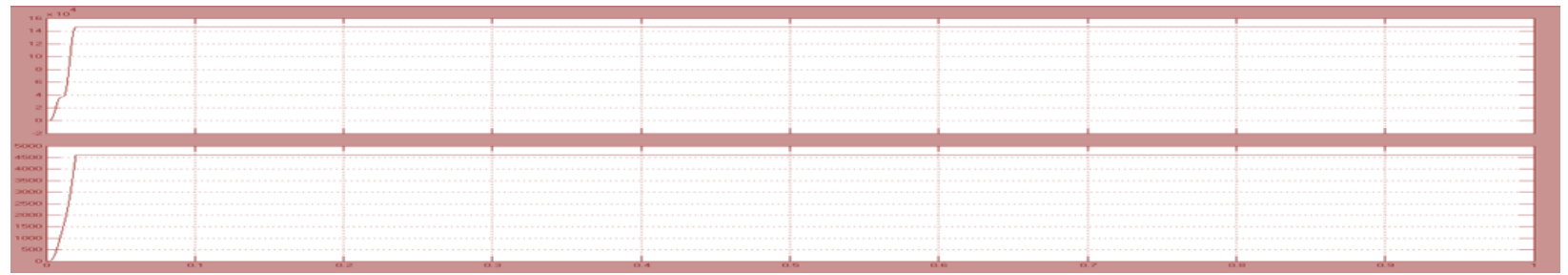

Fig 4:-Simulation output of real and reactive power with normal condition

\section{Transmission Line Model without Compensation:-}

The Simulink model of transmission line systems without compensation is shown in Fig 5. A power measurement block is connected in line 1 to measure real power and reactive power. The simulation output of current and voltage waveform of transmission model without compensation is shown in Fig 6. The Simulation output of real and reactive power without compensation is shown in Fig 7.

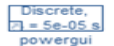

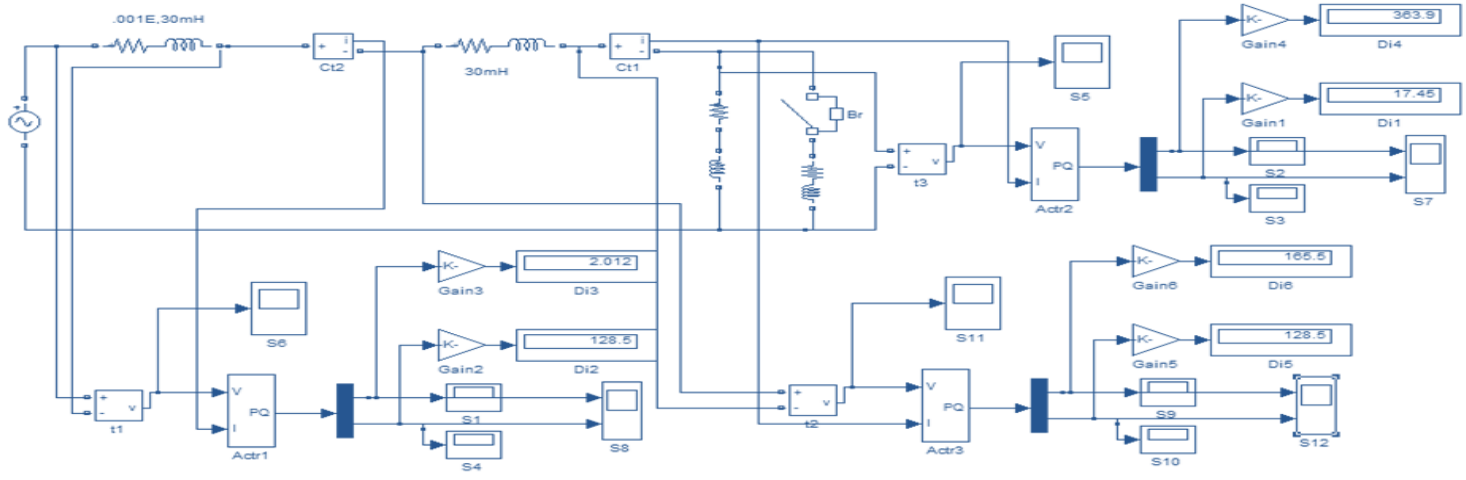

Fig 5:- Simulink model of transmission line without compensation.

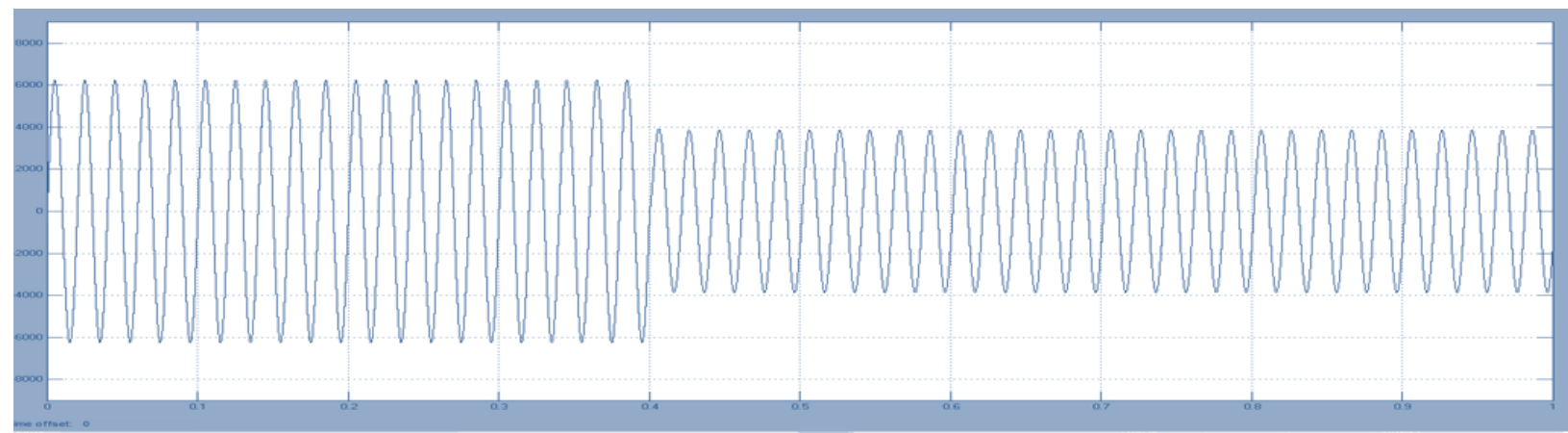

Fig 6:- Simulation output of voltage waveform without compensation. 


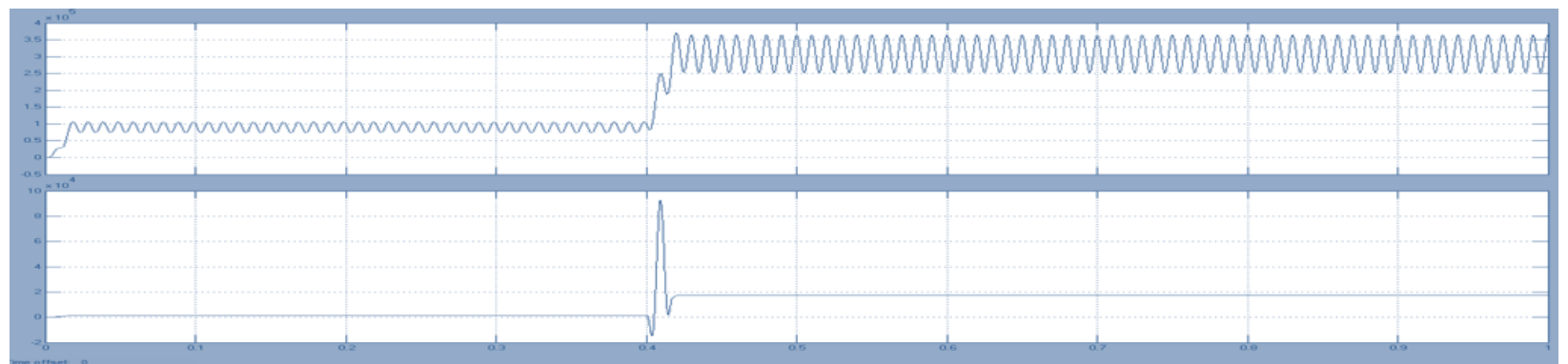

Fig 7:-.Simulation output of real and reactive power without compensation.

\section{Dynamic Voltage Restorer (DVR):-}

DVR is a series connected device which can control the load voltage by injecting the voltage from the DC link. The block diagram of dynamic voltage restorer as shown in Fig 8.

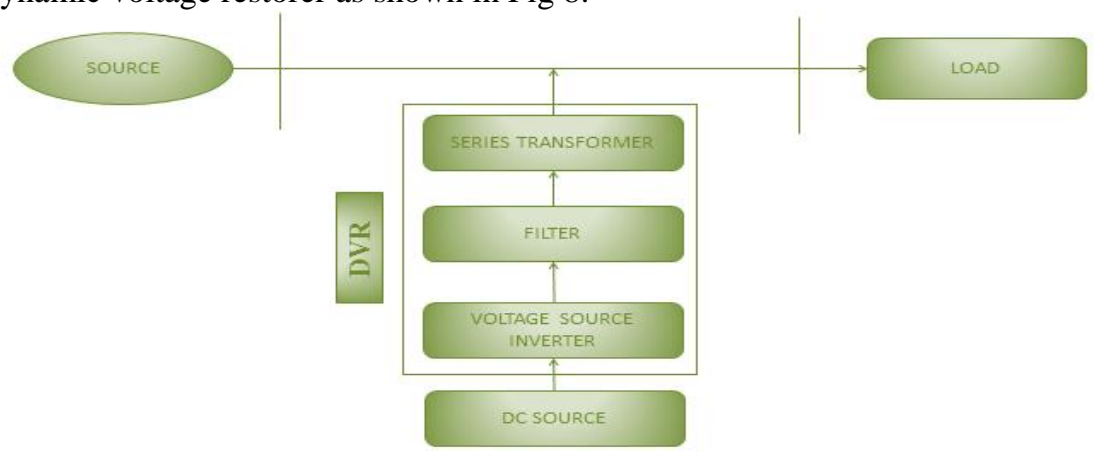

Fig 8:-.Block diagram of dynamic voltage restorer.

The Simulink model of transmission line systems with DVR is shown in Fig 9. A power measurement block is connected in line 1 to measure real power and reactive power. The simulation output of current and voltage waveform of transmission model with DVR is shown in Fig 10. The Simulation output of real and reactive power with DVR is shown in Fig 11.

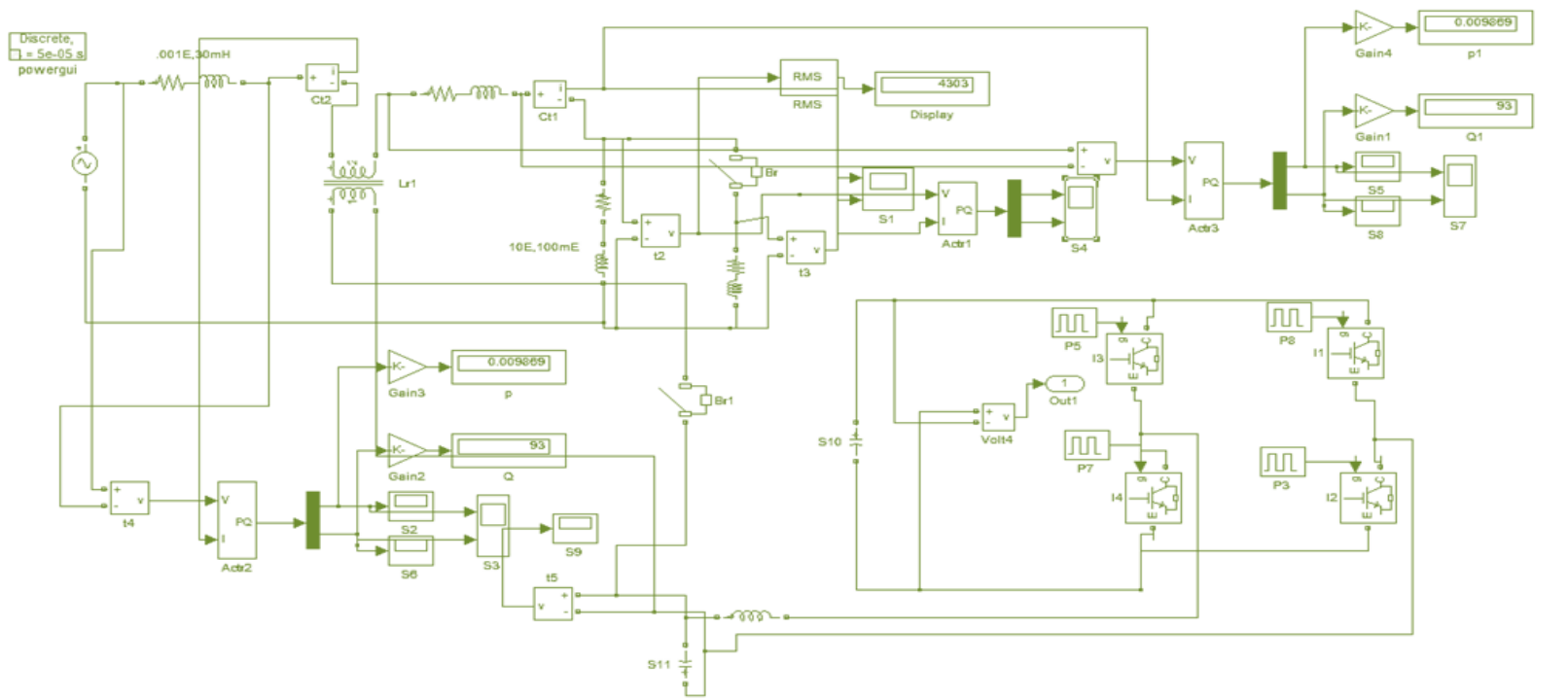

Fig 9:-.Simulink model of transmission line with dynamic voltage restorer. 


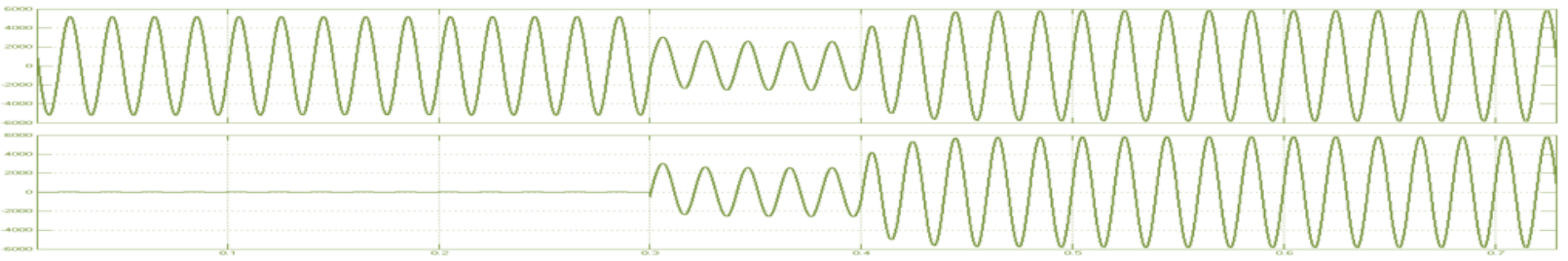

Fig 10:- Simulation output of voltage waveform with DVR.

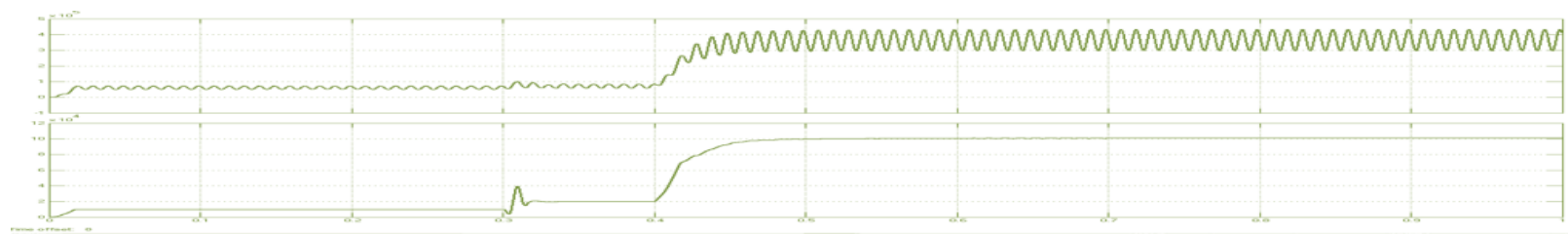

Fig 11:- .Simulation output of real and reactive power with DVR.

\section{Distributed Static Var Compensator (DSTATCOM):-}

DSTATCOM is a voltage source inverter based static compensator devices which control the level of bus voltage sag by supplying or absorbing the reactive power in the distribution system. The block diagram of DSTATCOM as shown in Fig 12.

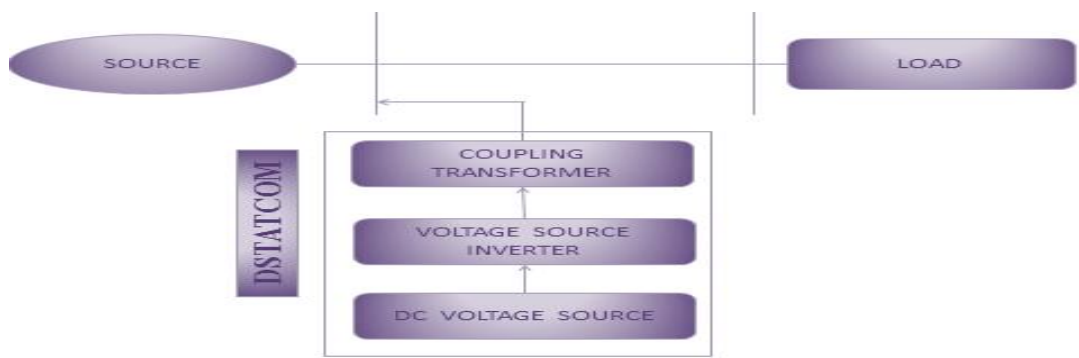

Fig 12:-.Block diagram of DSTATCOM.

The Simulink model of transmission line systems with DSTATCOM is shown in Fig 13. The simulation output of current and voltage waveform of transmission model with DSTATCOM is shown in Fig 14. The Simulation output of real and reactive power with DSTATCOM is shown in Fig 15.

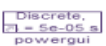

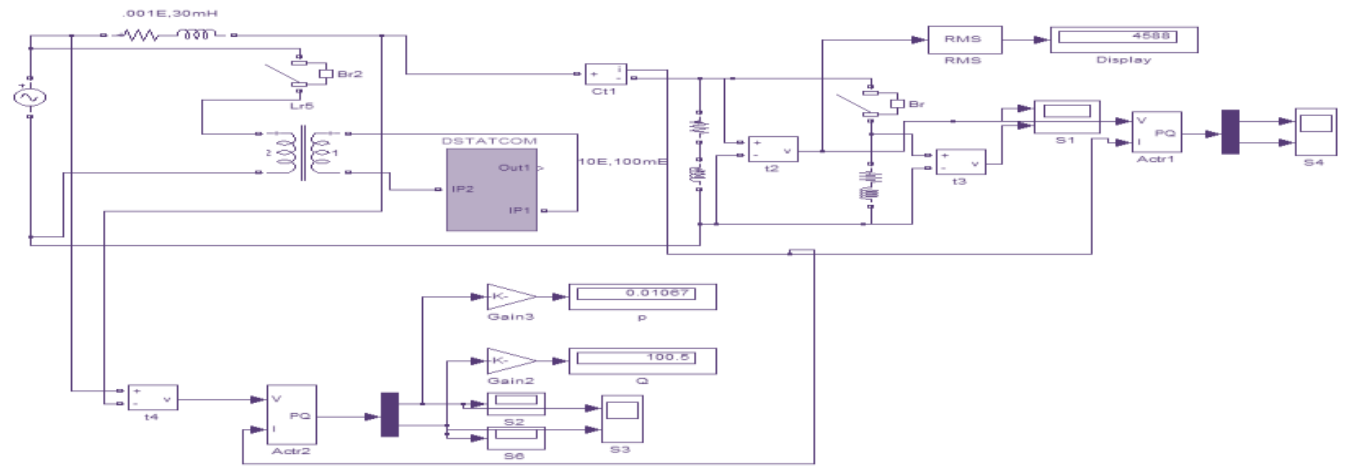

Fig 13:-. Simulink model of transmission line with DSTATCOM 


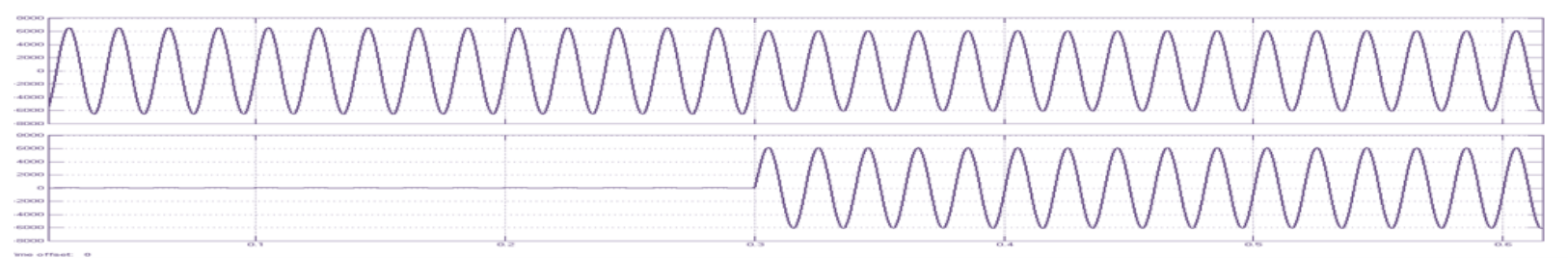

Fig 14:- Simulation output of voltage waveform with DSTATCOM..

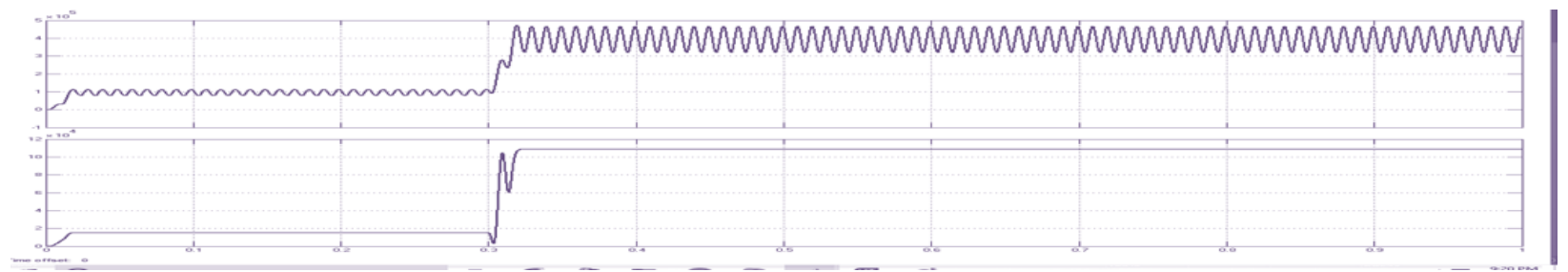

Fig 15:- Simulation output of real and reactive power with DSTATCOM

\section{Unified Power Flow Controller:-}

UPFC is a facts device to compensate the reactive power on high voltage electricity transmission networks. It is a combination of series and shunt converter with a common DC voltage link. The block diagram of unified power flow controller is shown in Fig 16.

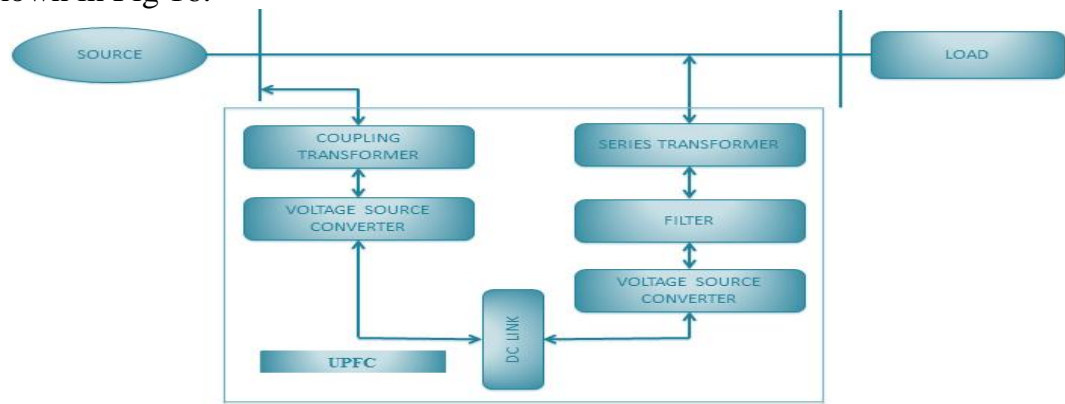

Fig 16:- .Block diagram of unified power flow controller.

The Simulink model of transmission line systems with UPFC is shown in Fig 17. The simulation output of current and voltage waveform of transmission model with UPFC is shown in Fig 18. The Simulation output of real and reactive power with UPFC is shown in Fig 19.

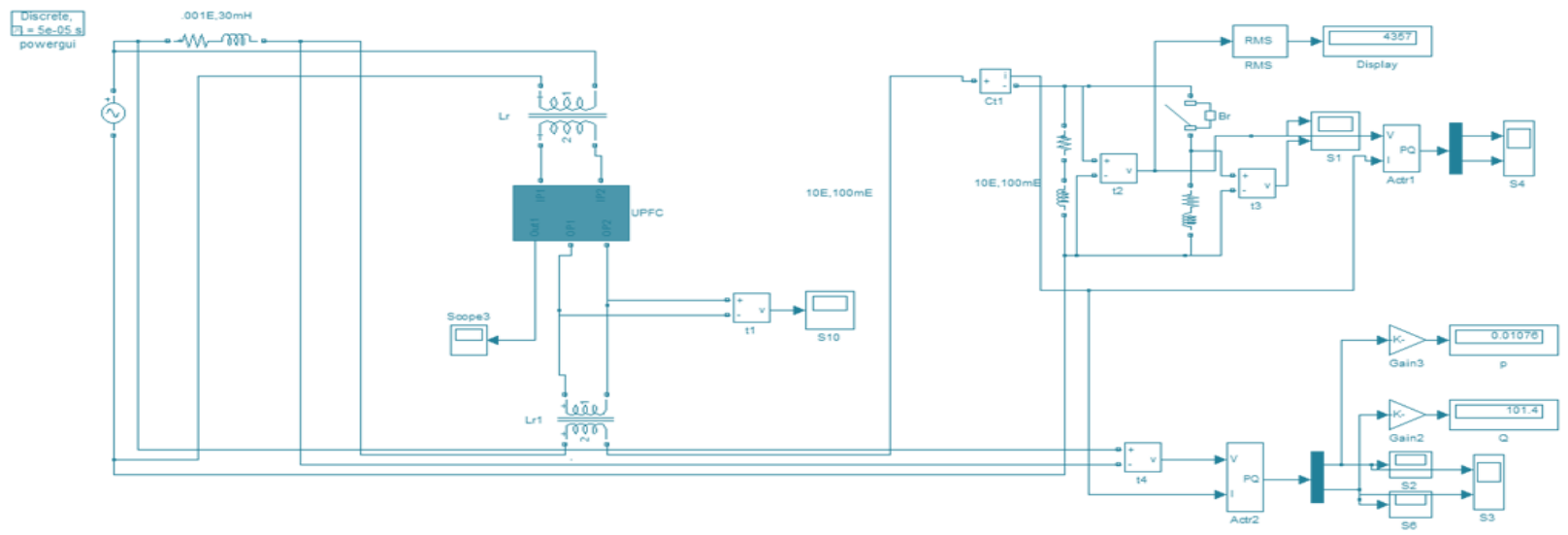

Fig 17:- Simulink model of transmission line with UPFC. 


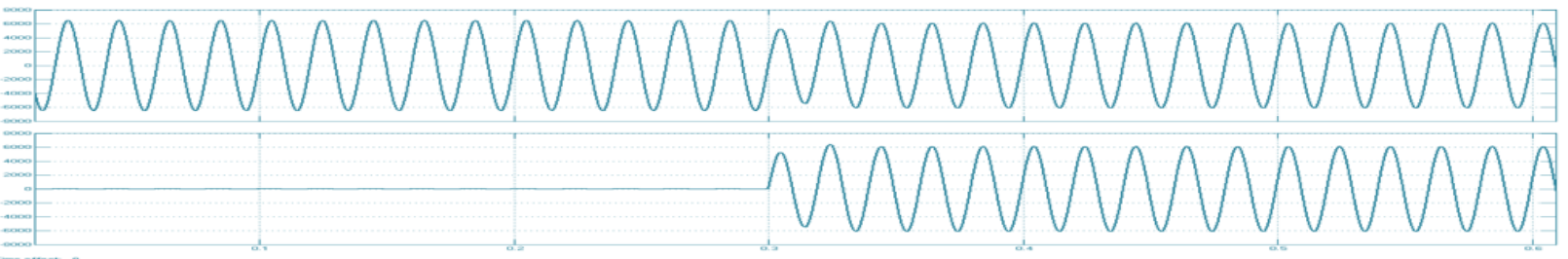

Fig 18:- .Simulation output of voltage waveform with UPFC.

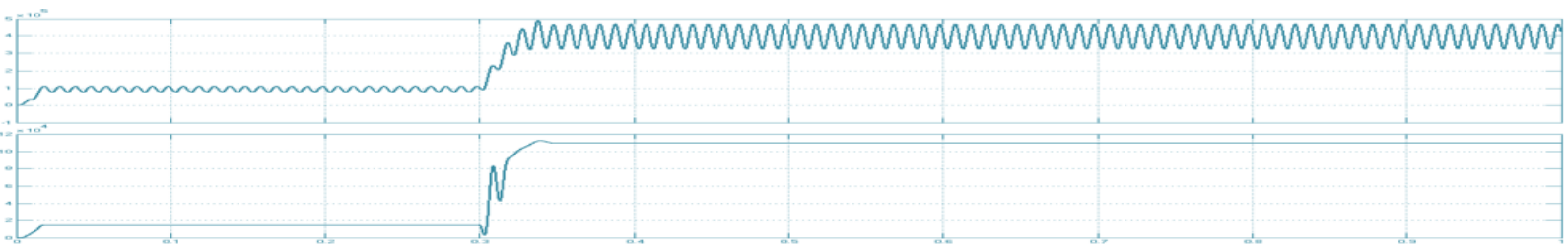

Fig 19:- Simulation output of real and reactive power with UPFC

Distributed Power Flow Controller:-

DPFC is facts device which use third harmonic frequency at a active power exchanges, between the shunt and series converters instead of common DC link. The block diagram of DPFC as shown in Fig 20

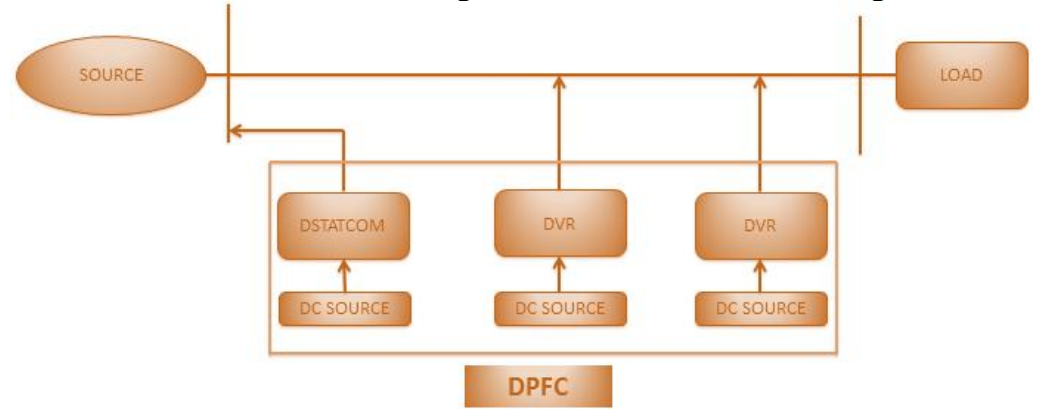

Fig 20:-Block diagram of distributed power flow controller.

The Simulink model of transmission line systems with DPFC is shown in Fig 21. The simulation output of current and voltage waveform of transmission model with DPFC is shown in Fig 22. The Simulation output of real and reactive power with DPFC is shown in Fig 23.

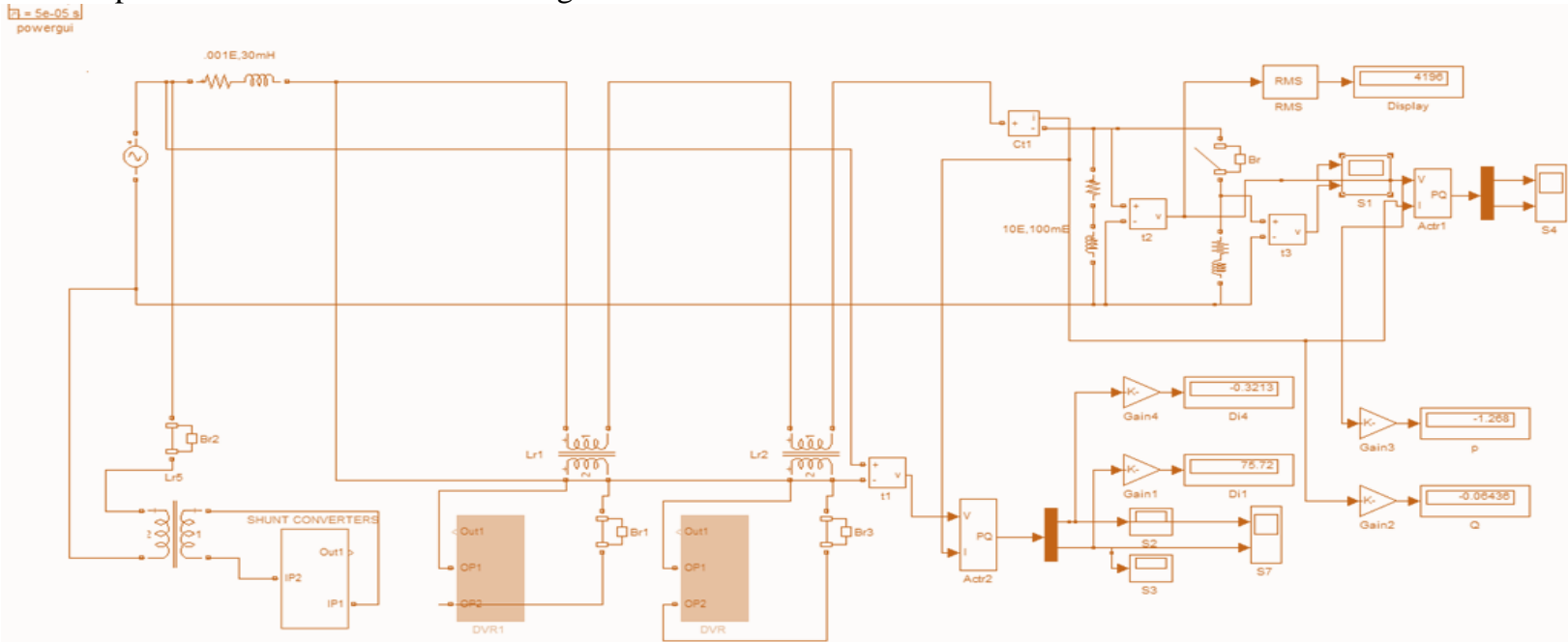

Fig 21:-Simulink model of transmission line with distributed power flow controller. 


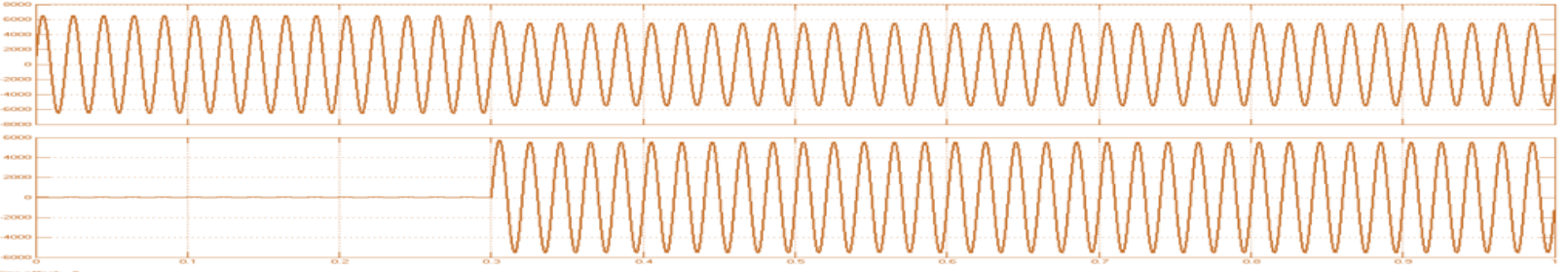

Fig 22:-Simulation output of voltage waveform with DPFC.

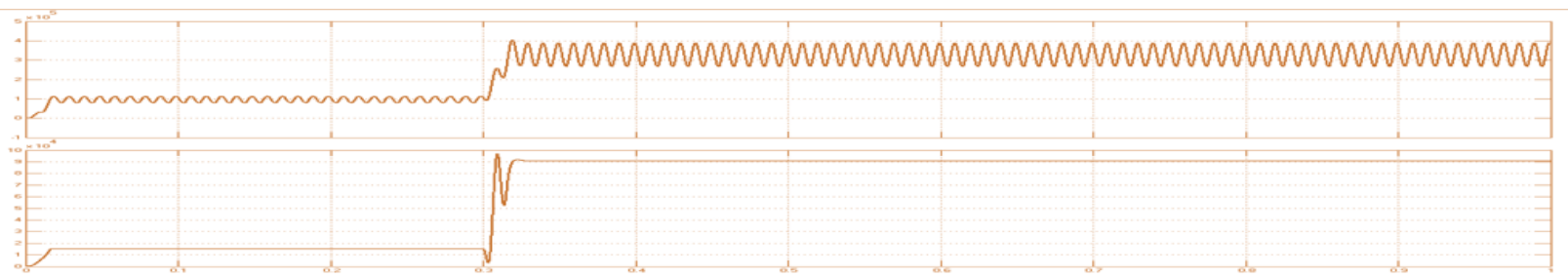

Fig 23:-.Simulation output of real and reactive power with DPFC.

Interline Dynamic Voltage Restorer (IDVR):-

The IDVR system consists of different DVRs protecting sensitive loads in different distribution feeders originate from different grid substations, and these DVRs share a common dc link. The block diagram of interline dynamic voltage restorer as shown in Fig 24.

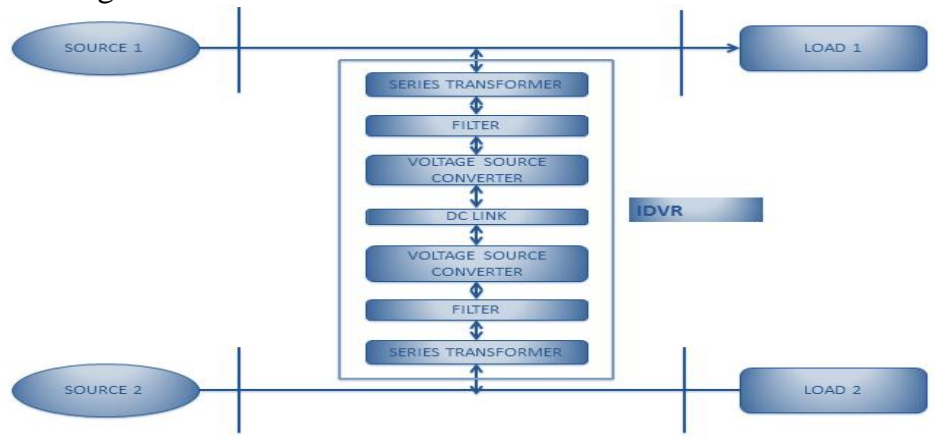

Fig 24:- Block diagram of interline dynamic voltage restorer.

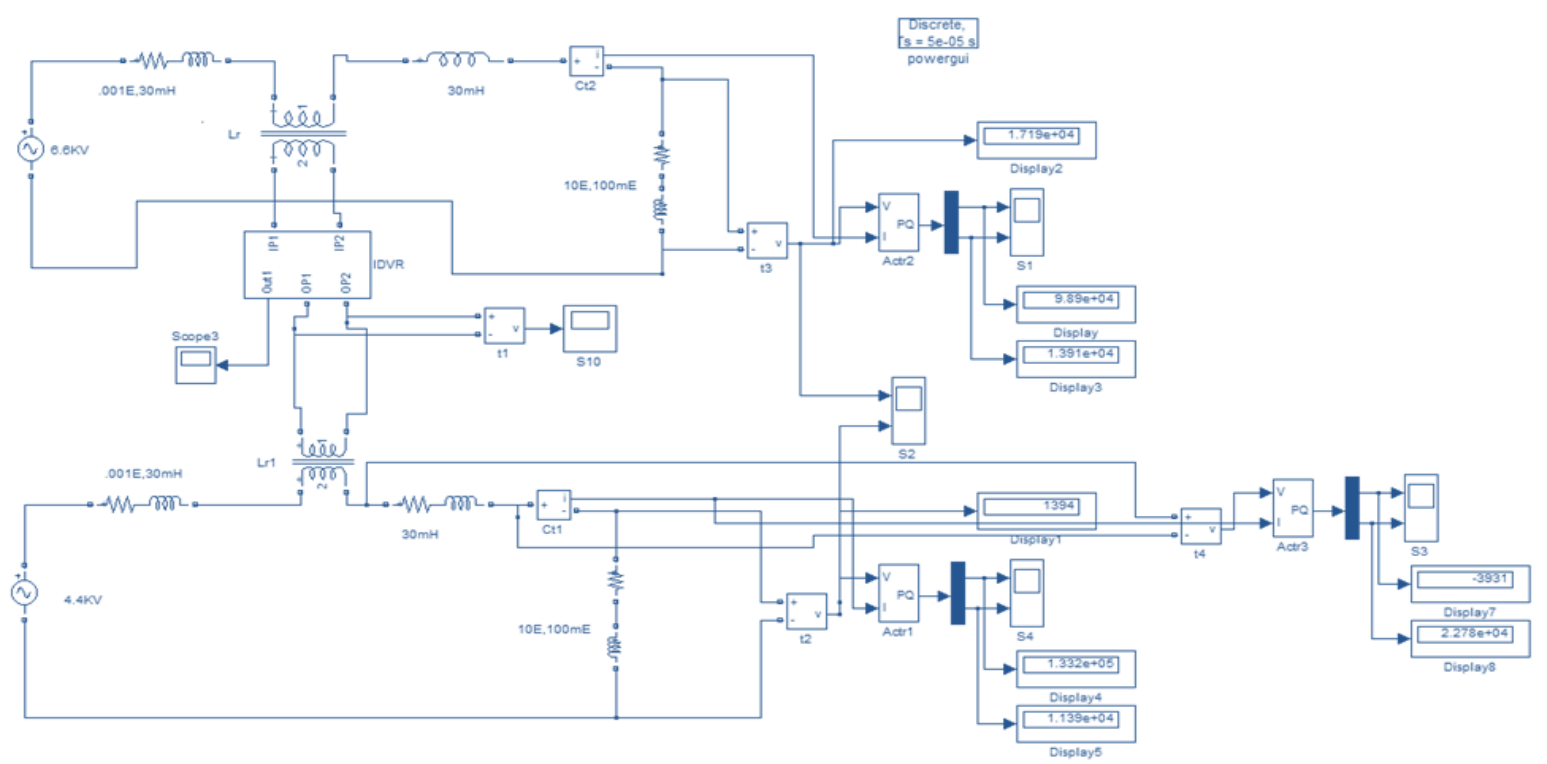

Fig 25:- Simulink model of two transmission line with interline dynamic voltage restorer. 
The Simulink model of transmission line systems with IDVR is shown in Fig 25. The simulation output of current and voltage waveform of transmission model with IDVR is shown in Fig 26. The Simulation output of real and reactive power with IDVR is shown in Fig 27.

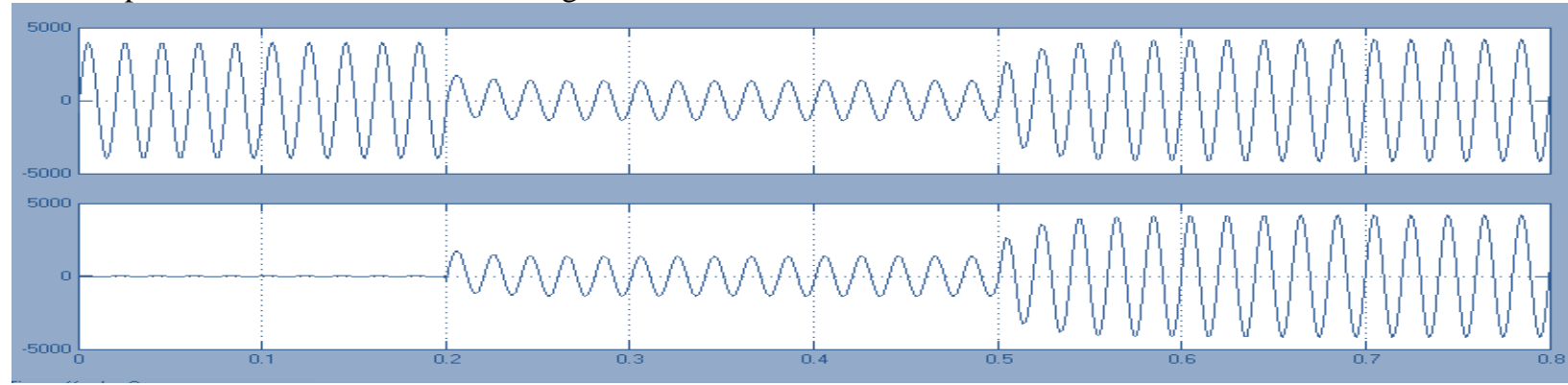

Fig 26:- Simulation output of voltage waveform with IDVR.

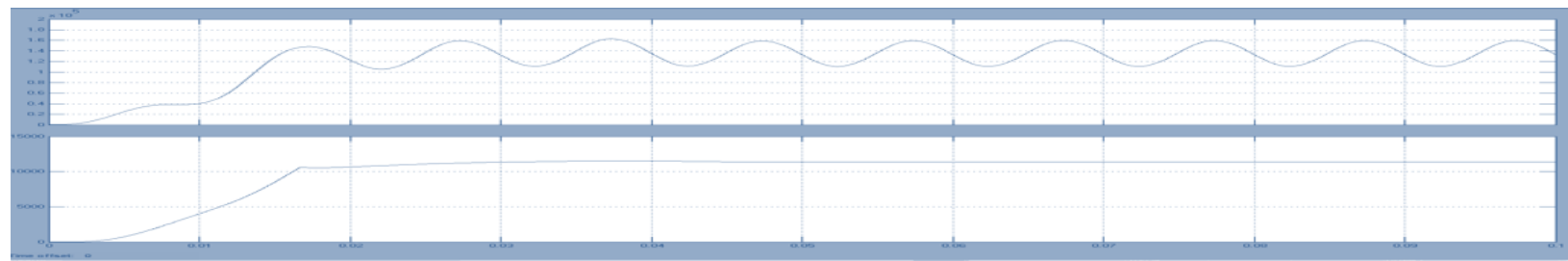

Fig 27:-.Simulation output of real and reactive power with IDVR.

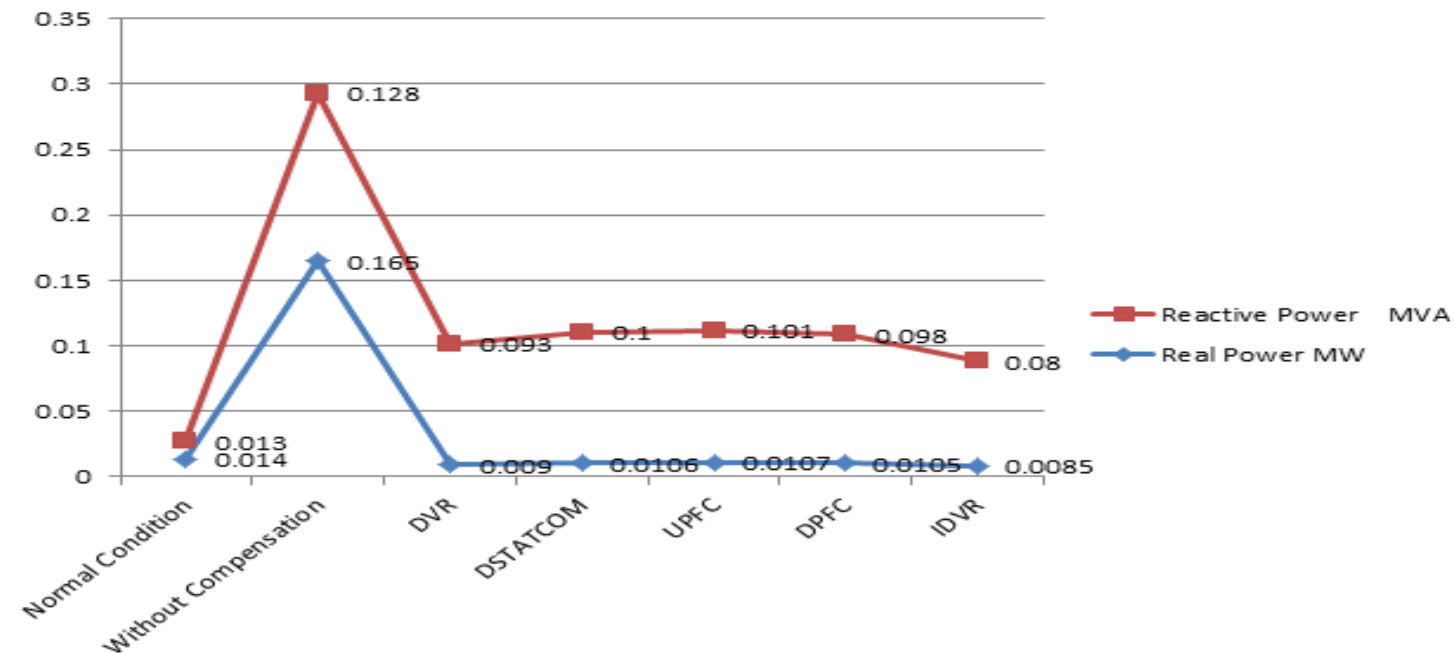

Graph 1:- Line Graph of Real and Reactive Power.

Table 1:- Comparison of Real and Reactive Power

\begin{tabular}{|c|c|c|c|}
\hline \multirow[t]{2}{*}{ Transmission Line } & \multicolumn{3}{|c|}{ Line Loss } \\
\hline & Real Power MW & Reactive Power & MVA \\
\hline Normal Condition & 0.0140 & $\mathbf{0 . 0 1 3}$ & \\
\hline Without Compensation & 0.1650 & 0.128 & \\
\hline DVR & 0.0090 & 0.093 & \\
\hline DSTATCOM & 0.0106 & 0.100 & \\
\hline UPFC & 0.0107 & 0.101 & \\
\hline DPFC & 0.0105 & 0.098 & \\
\hline IDVR & 0.0085 & 0.080 & \\
\hline
\end{tabular}




\section{Conclusion:-}

This paper describes the performance evaluation of custom power devices such as DVR, DSTATCOM, UPFC, DPFC and IDVR is analyzed. In this analysis the best custom devices to mitigate the voltage sag is found. The simulation results of all devices are obtained. . It shows that, the IDVR being the best results for the improvement of power quality. Among them device with less real and reactive losses during line interruption. The comparative results of all the devices are tabulated.

\section{References:-}

1. C. Alvarez, J. Alamar, A. Domijan Jr., A. Montenegro, and Song, "An investigationtowardnew technologies and issues in power quality, " in Proc. 9th Int. Conf Harmon. Qual. Power, vol. 2, 2000, pp. 444-449.

2. ArindamGhosh, Gerard Ledwich, "Power Quality Enhancement Using Custom PowerDevices" Kluwer Press, 2002.

3. M. L. Crow, "Power quality enhancement using custom power devices, " IEEE Power and Energy Magazine, vol.2, pp.50, April 2004

4. M.H. Haque, "Compensation of distribution system voltage sag by DVR and DSTATCOM," in Proc. IEEE Power Tech., vol.1, pp.5, Sept.2001.

5. H. Mehta, V. H. Tahiliani, J. E. Sullivan, "Custom Power: an opportunity for energyconversion, " in Proc of the International Conference on Electricity Distribution CIRED 1993, pp. 5.23/1- 5.23/6. 